\title{
Stiffness optimized research of high damping rubber bearing for beam bridges
}

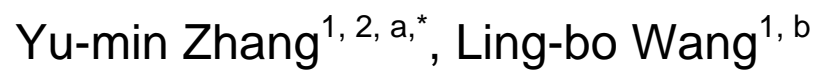 \\ ${ }^{1}$ School of Highways, Chang'an University, Xi'an 710064, China; \\ ${ }^{2}$ School of Mechanical Engineering, Xi'an ShiYou University, Xi'an 710061 ,China. \\ azhangyumincorn@163.com, bnancywlb1984@163.com
}

\begin{abstract}
Damping and isolation effect of high-damping rubber bearing with different combination have been studied for a continuous girder bridge. Dynamic time-history analysis has been taken by earthquake waves with exceeding probability to be 40 percent, 10 percent and 2 percent. The influence for seismic responses of bridge caused by sliding bearing set on transitional pier has been discuss. Research results show that the sliding bearings set on transitional piers have weakened the load sharing percent of transitional piers. The displacements of sliding bearings are larger than the bearings set on continuous piers, so that the load distribution of piers is nonuniform. The load sharing is much more reasonable when high-damping rubber bearings were set on all the piers, and the dynamical response of bridge was greatly decreases.
\end{abstract}

Keywords: beam bridge, high damping rubber bearing, stiffness, optimized research

\section{Introduction}

In order to reduce the damage of bridge under earthquake, seismic measures were be widely used in aseismic design of bridges, the seismic isolation bearing is one of the measures much more mature [1]. The high-damping rubber bearing (HDR) have the advantage of non-pollution, high-damping ratio, stable property and good durability, making HDR have the most widely application prospect [2].

The researches on high-damping rubber bearing were gradually increase by scholars at home or abroad [3]. Research found that high-damping rubber bearings have good seismic mitigation and isolation performance [4]. As the bearing to be use the seismic force of bridge can be reduce, the bearing can also confine the displacement of the whole structure and effectively control the earthquake response of the bridge [5]. Although the seismic mitigation and isolation performance of high-damper bearing was verified, the reasonable collocation method is not yet perfect. Aiming at obtain the optimal configuration of bearings, the high-damping rubber bearing with bearing Stiffness have been studied.

\section{Finite element model of bridge}

The engineering background was a continuous beam bridge with 4 spans of $50 \mathrm{~m}$, with the prestressed concrete T-beams as superstructure. The single width of cross section of superstructure was 12.15 meters, and the height of T-beam is 2.8 meters. The sections of piers were thin-walled hollow, with height of 35.5meters, 53.5meters, 75meters, 72 meters and 42.5meters respectively. Concrete C50 is used in superstructure and C40 in substructure.

The finite element analysis model of bridge was built by large finite element analysis software. The girder and piers were simulated as spatial beam element and pile caps were simulated to be fixed in the foundation.

The bridge site was in an aseismic region of VI degree fortification, time history analysis have been used by the earthquake waves with exceeding probability of $40 \%, 10 \%, 2 \%$ in 100 years. The earthquake wave with exceeding probability of $2 \%$ was shown in Fig.1. 


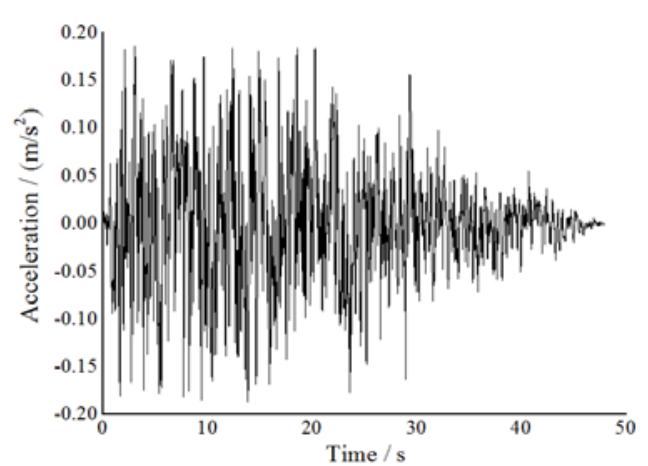

Fig.1 Earthquake wave with exceeding probability of $2 \%$

\section{Optimized research of bearing stiffness}

\subsection{Stiffness analysis of slide bearings}

According to the design scheme of high-damping rubber bearing, the slide high-damping rubber bearing LNR-420 $\times 520 \times 159$ have been suggest to be used on transition piers, and high-damping rubber bearing HDR-670×620×199 to continuous piers(case 1 ).

The dynamic time history analysis method was applied to analyze the seismic response of bridge with suggested high-damping rubber bearings. And the seismic response of bridge caused by axial large earthquakes with exceeding probability of $2 \%$ were list to be discuss in Tab. 1 .

Tab.1 Maximum seismic response of bridge with bearing combination case 1

\begin{tabular}{|c|c|c|c|c|}
\hline $\begin{array}{c}\text { Number } \\
\text { of piers }\end{array}$ & $\begin{array}{c}\text { Bending moment of } \\
\text { pier bottom / }(\mathrm{kN} \cdot \mathrm{m})\end{array}$ & $\begin{array}{c}\text { Shear force of pier } \\
\text { bottom / kN }\end{array}$ & $\begin{array}{c}\text { Displacement of } \\
\text { pier top / cm }\end{array}$ & $\begin{array}{c}\text { Displacement of } \\
\text { bearings / cm }\end{array}$ \\
\hline 1 & 76703 & 3899 & 4.74 & 43.48 \\
\hline 2 & 185082 & 4131 & 24.52 & 23.75 \\
\hline 3 & 190211 & 2878 & 35.68 & 12.67 \\
\hline 4 & 194358 & 3004 & 33.61 & 14.66 \\
\hline 5 & 106375 & 2877 & 8.80 & 39.30 \\
\hline
\end{tabular}

As the data shown in Tab.1, the bearing displacement and bottom shear force of transition piers were larger than continuous piers. The bearings displacement of pier 1 is $43.48 \mathrm{~cm}$, which is about 4 times more than pier 3 . The bottom bending moment and top displacement of transition piers were less than continuous piers. The top displacement of pier 1 is $4.74 \mathrm{~cm}$, which is about $1 / 8$ of pier 3 . The bottom bending moment of pier 3 is double of pier1. The results show that slide high-damper rubber bearing have reduce the seismic responses on transition piers, but is significantly different to continuous piers. The displacement of sliding rubber bearing is exceeds the allowable value $150 \mathrm{~mm}$.

\subsection{Impact analysis of high-damper bearing stiffness}

In order to decrease the oversize displacement of high-damper rubber bearing under earthquake, the bearing stiffness of transition piers have been increased. The type of bearing is changed from LNR420 $\times 470 \times 159$ to LNR620×670×204, and the horizontal stiffness changed from $2000 \mathrm{kN} / \mathrm{m}$ to $3000 \mathrm{kN} / \mathrm{m}$ with the increment $250 \mathrm{kN} / \mathrm{m}$ [6].

The dynamic time history analysis method was applied to analyze the seismic response of bridge with different LNR bearings. The changes of bearing displacement with stiffness have shown in Fig.2. 


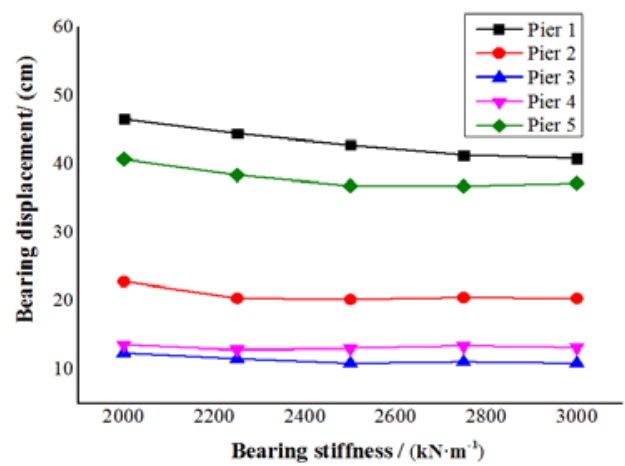

Fig. 2 The bearing displacement changed with LNR bearing stiffness

As the variation trend shown in Fig.2, the bearing displacement is decrease as the bearing stiffness increase. The bearing displacement of transition piers decrease more than continuous piers, the maximal decrease of bearings displacement is on pier 1 , which is decreased from $47 \mathrm{~cm}$ to $40 \mathrm{~cm}$. Although the bearing displacements of continuous piers have been controlled in reasonable range, the bearing displacement of transition piers was still exceeds the allowable value.

The slide bearings on transition piers were been suggest to change as high-damper bearings, so as to enhance the aseismic ability of bridge by increase the bearing stiffness. The type of bearing is changed from HDR420 $\times 470 \times 169$ to HDR620 $\times 670 \times 233$, and the initial horizontal stiffness changed from $2170 \mathrm{kN} / \mathrm{m}$ to $3260 \mathrm{kN} / \mathrm{m}$ with the increment $280 \mathrm{kN} / \mathrm{m}$. The dynamic time history analysis was used to analyze the seismic response of bridge with different HDR bearings. The changes of bearing displacement with HDR stiffness have shown in Fig.3.

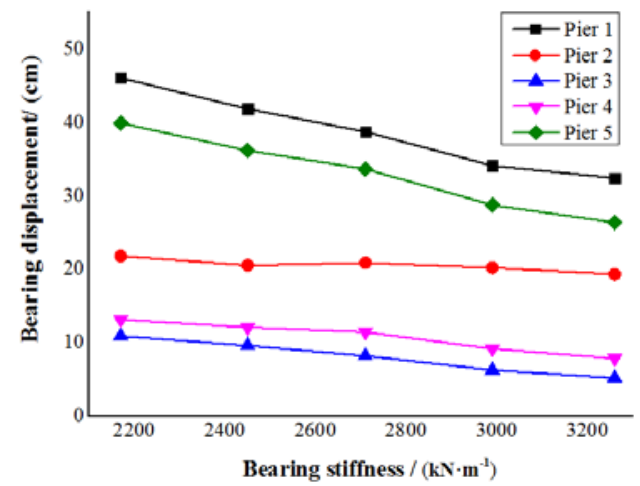

Fig.3 The bearing displacement changed with HDR bearing stiffness

As the variation trend shown in Fig.3, the bearing displacement is decrease as the bearing stiffness increase. The decrease extend of bearing displacement on pier 1 is maximum, which is decreased to $65 \%$ of the one with minimum stiffness. All the bearing displacements have been controlled in the allowable value $286 \mathrm{~mm}$.

By the analysis above, it is concluded that the seismic response of bridge was relatively more reasonable as the high-damping rubber bearings were set on side piers. So the high-damper bearing HDR (II) $620 \times 670 \times 233$ were been suggest to setting on bridge as recommendation(case2), the seismic response of bridge were list in Tab.2. 
Tab.2 Maximum seismic response of bridge with bearing combination case 2

\begin{tabular}{|c|c|c|c|c|c|c|c|c|}
\hline $\begin{array}{c}\text { Number } \\
\text { of piers }\end{array}$ & $\begin{array}{c}\text { Bending } \\
\text { moment } \\
\text { of pier } \\
\text { bottom / } \\
\text { (kN·m) }\end{array}$ & $\begin{array}{c}\text { Case 2 } \\
\text { /Case1 }\end{array}$ & $\begin{array}{c}\text { Shear } \\
\text { force of } \\
\text { pier } \\
\text { bottom / } \\
\mathrm{kN}\end{array}$ & $\begin{array}{c}\text { Case 2 } \\
\text { /Case1 }\end{array}$ & $\begin{array}{c}\text { Displacement } \\
\text { of pier top / } \\
\text { cm }\end{array}$ & $\begin{array}{c}\text { Case 2 } \\
\text { /Case1 }\end{array}$ & $\begin{array}{c}\text { Displacement } \\
\text { of bearings / } \\
\text { cm }\end{array}$ & $\begin{array}{c}\text { Case 2 } \\
\text { /Case1 }\end{array}$ \\
\hline 1 & 237811 & 3.10 & 5933 & 1.52 & 18.57 & 3.08 & 29.19 & 0.67 \\
\hline 2 & 207317 & 1.12 & 3837 & 0.93 & 18.57 & 1.13 & 16.09 & 0.68 \\
\hline 3 & 203915 & 1.07 & 3226 & 1.12 & 18.57 & 1.09 & 4.79 & 0.38 \\
\hline 4 & 200421 & 1.03 & 3474 & 1.16 & 18.57 & 1.06 & 7.81 & 0.53 \\
\hline 5 & 220366 & 2.07 & 4801 & 1.67 & 18.57 & 2.11 & 25.08 & 0.64 \\
\hline
\end{tabular}

As the seismic response shown in Tab.2, after the slide high-damping rubber bearings $(\mathrm{LNR}(\mathrm{H})-420 \times 520 \times 159)$ to be changed to HDR (II) $620 \times 670 \times 233$, the bottom bending moment, shear force and top displacement were increase, the largest increases of seismic response is on side piers. On the contrary, the displacements of bearings were nearly decreased to $60 \%$ of the case 1 as the stiffness of bearings was increased.

By the analysis above, it is obviously that the seismic response of bridge was relatively reasonable as the stiffness of high-damping rubber bearings increased. Although the slide bearings have isolation effect, their displacement were excessively large than the design displacement. The seismic response of bridge was relatively reasonable as the high-damping rubber bearings were set on all piers, and earthquake load was equally separated. The bearing displacement of transition piers were relatively decreased, to be effectively controlled less than its limiting displacement 429mm.

\section{Conclusions}

The displacement of slide bearings set on transition piers were generally larger than other bearings, some were 4 times more than continuous piers and exceeded the allowable value. Slide high-damper rubber bearing have reduce the seismic responses on transition piers significantly, but the load distribution were unbalanced among piers.

The bearing stiffness of transition piers have been increased to decrease the oversize displacement of high-damper rubber bearing under earthquake. Result show that the bearing displacement is decrease in a certain extent as the bearing stiffness increase, but the effect is not ideal.

As the bearing of transition piers to be changed to same high-damping rubber bearings, the seismic responses of bridge have been effectively control. The earthquake load was equally separated and bearing displacements of side piers were relatively decreased less than limiting displacement.

\section{Acknowledgments}

This work was financially supported by Scientific Research Program Funded by Shaanxi Provincial Education Department (Program No.12JK0900) and Innovation and Technology Fund of Xi'an ShiYou University (Program No.2013BS019).

\section{References}

[1] Chen Yan-jiang, Guo Kai-min, Li Yong. Behavior of high-damping seismic isolation rubber bearings for bridges. Journal of vibration and shock, 34(2015) 136-148.

[2] He Zeng, Song Xuming, Ling Yi, Leng Yu. Applicability study of high-damping rubber bearing in curved box girder. Journal of Railway Science and Engineering, 13(2016) 2081-2188.

[3] Zhuang Xuezhen, Shen Chaoyong, Jin Jianmin. Experimental study on mechanical property of high-damping rubber bearing for bridge. Earthquake Engineering and Engineering Vibration, 26(2006)208-212. 
[4] Mahmoud, S., Austrell, PE. \& Jankowski, R. Simulation of the response of base-isolated buildings under earthquake excitations considering soil flexibility. Earthquake Engineering and Engineering Vibration, 11(2012) 359-374.

[5] Yamamoto K, Fujita I and Takewaki, "Instantaneous Earthquake Input Energy and Sensitivity in Base-isolated Building,” the Structural Design of Tall and Special Buildings, 20(2011)631- 648.

[6] JT/T 842-2012, High-damping seismic isolation rubber bearings for highway bridges [S] 